\title{
Vibration Analysis of Beams with and without Cracks Using the Composite Element Model
}

\author{
Z.R. Lu, M. Huang and J.K. Liu \\ Sun Yat-sen University \\ P.R. China
}

\section{Introduction}

Beams are fundamental models for the structural elements of many engineering applications and have been studied extensively. There are many examples of structures that may be modeled with beam-like elements, for instance, long span bridges, tall buildings, and robot arms.

The vibration of Euler-Bernoulli beams with one step change in cross-section has been well studied. Jang and Bert (1989) derived the frequency equations for combinations of classical end supports as fourth order determinants equated to zero. Balasubramanian and Subramanian (1985) investigated the performance of a four-degree-of-freedom per node element in the vibration analysis of a stepped cantilever. De Rosa (1994) studied the vibration of a stepped beam with elastic end supports. Recently, Koplow et al. (2006) presented closed form solutions for the dynamic response of Euler-Bernoulli beams with step changes in cross section.

There are also some works on the vibration of beams with more than one step change in cross-section. Bapat and Bapat (1987) proposed the transfer matrix approach for beams with n-steps but provided no numerical results. Lee and Bergman (1994) used the dynamic flexibility method to derive the frequency equation of a beam with n-step changes in crosssection. Jaworski and Dowell (2008) carried out a study for the free vibration of a cantilevered beam with multiple steps and compared the results of several theoretical methods with experiment.

A new method is presented to analyze the free and forced vibrations of beams with either a single step change or multiple step changes using the composite element method (CEM) (Zeng, 1998; Lu \& Law, 2009). The correctness and accuracy of the proposed method are verified by some examples in the existing literatures. The presence of cracks in the structural components, for instance, beams can have a significant influence on the dynamic responses of the whole structure; it can lead to the catastrophic failure of the structure. To predict the failure, vibration monitoring can be used to detect changes in the dynamic responses and/or dynamic characteristics of the structure. Knowledge of the effects of cracks on the vibration of the structure is of importance. Efficient techniques for the forward analysis of cracked beams are required. To this end, the composite element method is then extended for free and forced vibration analysis of cracked beams.

The principal advantage of the proposed method is that it does not need to partition the stepped beam into uniform beam segments between any two successive discontinuity points 
and the whole beam can be treated as a uniform beam. Moreover, the presented work can easily be extended to cracked beams with an arbitrary number of non-uniform segments.

\section{Theory}

\subsection{Introduction to Composite Element Method (CEM)}

The composite element is a relatively new tool for finite element modeling. This method is basically a combination of the conventional finite element method (FEM) and the highly precise classical theory (CT). In the composite element method, the displacement field is expressed as the sum of the finite element displacement and the shape functions from the classical theory. The displacement field of the CEM can be written as

$$
u_{C E M}(x, t)=u_{F E M}(x, t)+u_{C T}(x, t)
$$

where $u_{F E M}(x, t)$ and $u_{C T}(x, t)$ are the individual displacement fields from the FEM and CT, respectively.

Taking a planar beam element as an example, the first term of the CEM displacement field can be expressed as the product of the shape function vector of the conventional finite element method $N(x)$ and the nodal displacement vector $q$

$$
u_{F E M}(x, t)=N(x) q(t)
$$

where $q(t)=\left[v_{1}(t), \theta_{1}(t), v_{2}(t), \theta_{2}(t)\right]^{T}$ and ' $v$ ' and ' $\theta$ ' represent the transverse and rotational displacements, respectively.

The second term $u_{C T}(x, t)$ is obtained by the multiplication of the analytical mode shapes with a vector of $N$ coefficients $c$ ( also called the $c$ degrees-of-freedom or $c$-coordinates).

$$
u_{C T}(x, t)=\sum_{i=1}^{N} \varphi_{i}(x) c_{i}(t)
$$

where $\varphi_{i}(i=1,2, \ldots N)$ is the analytical shape function of the beam. Different analytical shape functions are used according to the boundary conditions of the beam.

Like the FEM, the CEM can be refined using the $h$-refinement technique by increasing the number of finite elements. Moreover, it can also be refined through the $c$-refinement method, by increasing the number of shape functions. Here, we apply the $c$-refinement from the CEM, where the beam needs only to be discretized into one element. This will reduce the total number of degrees-of-freedom in the FEM.

The displacement field of the CEM for the Euler-Bernoulli beam element can be written from Equations (1) to (3) as

$$
u_{C E M}(x, t)=S(x) Q(t)
$$

where $S(x)=\left[N_{1}(x), N_{2}(x), N_{3}(x), N_{4}(x), \phi_{1}(x), \phi_{2}(x), \ldots, \phi_{N}(x)\right]$ is the generalized shape function of the CEM, $Q(t)=\left[v_{1}(t), \theta_{1}(t), v_{2}(t), \theta_{2}(t), c_{1}(t), c_{2}(t), \ldots, c_{N}(t)\right]^{T}$ is the vector of generalized displacements, and $N$ is the number of shape functions used from the classical theory. 


\subsection{Vibration analysis for stepped beams without crack}

Figure 1 shows the sketch of a beam with $n$ steps, the height of the beam $d(x)$ with $n$ step changes in cross section is expressed as

$$
d(x)=\left\{\begin{array}{cc}
d_{1} & 0 \leq x<L_{1} \\
d_{2} & L_{1} \leq x \leq L_{2} \\
& \vdots \\
d_{n} & L_{n-1} \leq x \leq L_{n}
\end{array}\right.
$$

It is assumed that the beam has aligned neutral axis, the flexibility of the beam $\operatorname{EI}(x)$ can be expressed as

$$
E I(x)=\left\{\begin{array}{cc}
\frac{w d_{1}^{3}}{12} & 0 \leq x<L_{1} \\
\frac{w d_{2}^{3}}{12} & L_{1} \leq x \leq L_{2} \\
\vdots \\
\frac{w d_{n}^{3}}{12} & L_{n-1} \leq x \leq L_{n}
\end{array}\right.
$$

where $w$ is the width of the beam. For the stepped beam with misaligned neutral axes, the expression of $E I(x)$ can not expressed simply as shown in Equation (6).

The beam mass per unit length is

$$
m(x)=\left\{\begin{array}{cc}
\rho w d_{1} & 0 \leq x<L_{1} \\
\rho w d_{2} & L_{1} \leq x \leq L_{2} \\
& \vdots \\
\rho w d_{n} & L_{n-1} \leq x \leq L_{n}
\end{array}\right.
$$

where $\rho$ is the mass density of the beam.

The elemental stiffness matrix of the stepped beam can be obtained from the following equation

$$
\mathbf{K}_{\mathbf{e}}=\int_{0}^{L} \frac{d^{2} S^{T}}{d x^{2}} E I(x) \frac{d^{2} S}{d x^{2}} d x=\left[\begin{array}{ll}
{\left[k_{q q}\right]} & {\left[k_{q c}\right]} \\
{\left[k_{c q}\right]} & {\left[k_{c c}\right]}
\end{array}\right]
$$

where the submatrix $\left[k_{q q}\right]$ corresponds to the element stiffness matrix from the FEM for the stepped beam; the submatrix $\left[k_{q c}\right]$ corresponds to the coupling terms of the $q$-dofs and the $c$-dofs; submatrix $\left[k_{c q}\right]$ is a transpose matrix of $\left[k_{q c}\right]$, and the submatrix $\left[k_{c c}\right]$ corresponds to the $c$-dofs and is a diagonal matrix.

The consistent elemental mass matrix can be expressed as

$$
\mathbf{M}_{\mathbf{e}}=\int_{0}^{L} S(x)^{T} m(x) S(x) d x=\left[\begin{array}{ll}
{\left[m_{q q}\right]} & {\left[m_{q c}\right]} \\
{\left[m_{c q}\right]} & {\left[m_{c c}\right]}
\end{array}\right]
$$


where the submatrix $\left[m_{q q}\right]$ corresponds to the elemental mass matrix from the FEM for the stepped beam; the submatrix $\left[m_{q c}\right]$ corresponds to the coupling terms of the $q$-dofs and the $c$-dofs; submatrix $\left[m_{c q}\right]$ is a transpose matrix of $\left[m_{q c}\right]$, and the submatrix $\left[m_{c c}\right]$ corresponds to the $c$-dofs and is a diagonal matrix.

After introducing the boundary conditions, this can be performed by setting the associated degrees-of-freedom in the systematic stiffness matrix $\mathbf{K}$ to be a large number, say, $10^{12}$, the governing equation for free vibration of the beam can be expressed as

$$
\left(\mathbf{K}-\omega^{2} \mathbf{M}\right) V=0
$$

where $\mathbf{K}$ and $\mathbf{M}$ are system stiffness and mass matrices, respectively, $\omega$ is the circular frequency, from which and the natural frequencies are identified. The $i$ th normalized mode shapes of the stepped beam can be expressed as

$$
\Psi_{i}=\sum_{i=1}^{4} N_{i} V_{i}+\sum_{i=1}^{N} \varphi_{i} V_{i+4}
$$

The equation of motion of the forced vibration of the beam with $n$ steps when expressed in terms of the composite element method is

$$
\mathbf{M} \ddot{Q}+\mathbf{C} \dot{Q}+\mathbf{K} Q=f(t)
$$

where $\mathbf{M}$ and $\mathbf{K}$ are the system mass and stiffness matrices, which are the same as those shown in Equation (10), $\mathbf{C}$ is the damping matrix which represents a Rayleigh damping model,say, $\mathbf{C}=a_{1} \mathbf{M}+a_{2} \mathbf{K}, a_{1}$ and $a_{2}$ are constants to be determined from two modal damping ratios. For an external force $F(t)$ acting at the location $x_{F}$ from the left support, the generalized force vector $f(t)$ can be expressed as

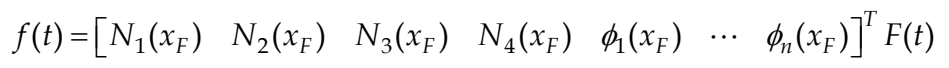

The generalized acceleration $\ddot{Q}$, velocity $\dot{Q}$ and displacement $Q$ of the stepped beam can be obtained from Equation (12) by direct integration. The physical acceleration $\ddot{u}(x, t)$ is obtained from

$$
\ddot{u}(x, t)=[S(x)]^{T} \ddot{Q}
$$

The physical velocity and displacement can be obtained in a similar way, i.e.

$$
\begin{aligned}
& \dot{u}(x, t)=[S(x)]^{T} \dot{Q}, \\
& u(x, t)=[S(x)]^{T} Q
\end{aligned}
$$

\subsection{The crack model}

Numerous crack models for a cracked beam can be found in the literature. The simplest one is a reduced stiffness (or increased flexibility) in a finite element to simulate a small crack in the element (Pandey et al., 1991; Pandy \& Biswas, 1994). Another simple approach is to divide the cracked beam into two beam segments joined by a rotational spring that 
represents the cracked section (Rizos et al., 1990; Chaudhari \& Maiti, 2000). Christides and Barr (1984) developed the one-dimensional vibration theory for the lateral vibration of a cracked Euler-Bernoulli beam with one or more pairs of symmetric cracks.

According to Christides and Barr(1984), the variation of bending stiffness $E I_{d}(x)$ along the cracked beam length takes up the form of

$$
E I_{d}(x)=\frac{E I_{0}}{1+(c-1) \exp \left(-2 \alpha\left|x-x_{c}\right| / d\right)}
$$

where $E$ is the Young's modulus of the beam, $I_{0}=w d^{3} / 12$ is the second moment of area of the intact beam, $c=1 /\left(1-C_{r}\right)^{3}, C_{r}=d_{c} / d$ is the crack depth ratio and $d_{c}$ and $d$ are the depth of crack and the beam, respectively, $x_{c}$ is the location of the crack. $\alpha$ is a constant which governs the rate of decay and it is estimated by Christides and Barr from experiments to be 0.667 . According to Lu and Law (2009), this parameter needs to be adjusted to be 1.426 .

\subsection{Vibration analysis for beams with crack(s)}

The elemental stiffness matrix of the cracked beam can be obtained from the following equation

$$
\mathbf{K}_{\mathbf{e}}=\int_{0}^{L} \frac{d^{2} S^{T}}{d x^{2}} E I_{d}(x) \frac{d^{2} S}{d x^{2}} d x=\left[\begin{array}{ll}
{\left[k_{q q}\right]} & {\left[k_{q c}\right]} \\
{\left[k_{c q}\right]} & {\left[k_{c c}\right.}
\end{array}\right]
$$

It is assumed that the existence of crack does not affect the elemental mass matrix, the elemental mass matrix can be expressed in the similar way with the intact beam

$$
\mathbf{M}_{\mathbf{e}}=\int_{0}^{L} S(x)^{T} m(x) S(x) d x=\left[\begin{array}{ll}
{\left[m_{q q}\right]} & {\left[m_{q c}\right]} \\
{\left[m_{c q}\right]} & {\left[m_{c c}\right]}
\end{array}\right]
$$

The equation of motion of the forced vibration of a cracked beam with $n$ cracks when expressed in terms of the composite element method is

$$
\mathbf{M} \ddot{Q}+\mathbf{C} \dot{Q}+\mathbf{K}\left(x_{L_{1}}, d_{c_{1}}, \ldots, x_{L_{i}}, d_{c_{i}}, \ldots x_{L_{n}}, d_{c_{n}}\right) Q=f(t)
$$

\section{Applications Information}

\subsection{Free and forced vibration analysis for beam without crack}

\subsubsection{Free vibration analysis for a free-free beam with a single step}

The free vibration of the free-free beam studied in Koplow et al. (2006) is restudied using the CEM and the results are compared with those in Koplow et al. Figure 2 shows the geometry of the beam under study. The material has a mass density of $\rho=2830 \mathrm{~kg} / \mathrm{m}^{3}$, and a Young's modulus of $E=71.7 \mathrm{GPa}$. In the CEM when 350 numbers of c-dofs are used, the first three natural frequencies are converged. The first three natural frequencies of the beam are $291.9 \mathrm{~Hz}, 1176.2 \mathrm{~Hz}$ and $1795.7 \mathrm{~Hz}$, respectively. The calculated natural frequencies from the CEM are very close to the experimental values in Koplow et al. when the test is measured at location A in Figure 2, which are $291 \mathrm{~Hz}, 1165 \mathrm{~Hz}$ and $1771 \mathrm{~Hz}$, respectively. The relative 
errors between the CEM and the experimental values of the three natural frequencies are $0.31 \%, 0.96 \%$ and $1.39 \%$, respectively. This shows the proposed method is accuracte.

\subsubsection{Free vibration analysis for a cantilever beam with a several steps}

The cantilever beam studied in Jaworski and Dowell (2008) is restudied to further check the accuracy and effectiveness of the proposed method. Figure 3 shows the dimensions of the beam under study. The parameters of the beam under study are: $E=60.6 \mathrm{GPa}$ and $\rho=2664 \mathrm{~kg} / \mathrm{m}^{3}$. In the CEM model of the beam, the beam is discretized into one element and 350 terms of c-dofs are used in the calculation. The first and second flapwise (out-ofplane) bending mode frequencies are calculated to be $10.758 \mathrm{~Hz}$ and $67.553 \mathrm{~Hz}$, and the first chordwise (in-plane) bending mode frequency is $54.699 \mathrm{~Hz}$. The results from the CEM agree well with the theoretical results in Jaworski and Dowell using Euler-Bernoulli theory, as shown in Table 1.

\subsubsection{Forced vibration analysis for a cantilever beam with two steps}

In this section, the forced vibration analysis for the stepped beam is investigated. The dynamic responses of the beam under external force are obtained from the CEM and the results are compared with those from the FEM. Figure 4 shows the cantilever beam under study. The parameters of the beam under study are $E=69.6 \mathrm{GPa}$ and $\rho=2700 \mathrm{~kg} / \mathrm{m}^{3}$. A sinusoidal external force is assumed to act at free end of the beam with a magnitude of $1 \mathrm{~N}$ and at a frequency of $10 \mathrm{~Hz}$. The time step is 0.005 second in calculating the dynamic response. The Rayleigh damping model is adopted in the calculation with 0.01 and 0.02 as the first two modal damping ratios. In the CEM model, the beam is discretized into one element and $350 \mathrm{c}$-dofs are used in the calculation of the dynamic responses. Figure 5 shows the displacement response, velocity response and acceleration response at the free end of the beam. In order to check the accuracy of the responses from the CEM, a forced vibration analysis for the beam is conducted using the FEM. The beam is discretized into 90 EulerBernoulli beam elements with a total of 182 dofs. The corresponding responses from the FEM and the CEM are compared in Figure 5. This indicates the accuracy of the proposed method for forced vibration of multiple stepped beam. Figure 6 gives a close view between the responses from two methods. From this figure, one can see that the two time histories in every subplot are virtually coincident indicating the excellent agreement between the time histories.

\subsection{Free and forced vibration analysis for beam with crack}

\subsubsection{Free vibration analysis for a uniform cantilever beam with a single crack}

An experimental work in Sinha et al. (2002) is re-examined. The geometric parameters of the beam are: length $996 \mathrm{~mm}$, width $50 \mathrm{~mm}$, depth $25 \mathrm{~mm}$, material properties of the beam are: Young's modulus $E=69.79 \mathrm{GPa}$, mass density $\rho=2600 \mathrm{~kg} / \mathrm{m}^{3}$. The beam is discretized into one element and ten shape functions are used in the calculation with the total degrees-offreedom in the CEM equals 14, while the total degrees-of-freedom in the finite element model is 34 for the beam in Sinha et al. The crack depth in the beams varies in three stages of $4 \mathrm{~mm}, 8 \mathrm{~mm}$ and $12 \mathrm{~mm}$. The comparison of predicted natural frequencies of the beam from the proposed model and those in Sinha et al. and the experimental results are shown in Table 2. The proposed model, in general, gives better results than the model in Sinha et al. 
since the latter crack model is a linear approximation of the theoretical crack model of Christides and Barr.

\subsubsection{Free vibration analysis for a cantilever beam with multiple cracks}

The last beam above is studied again with a new crack introduced. The first crack is at $595 \mathrm{~mm}$ from the left end with a fixed crack depth of $12 \mathrm{~mm}$ while the second crack is at $800 \mathrm{~mm}$ from the left end with the crack depth varying from $4 \mathrm{~mm}$ to $12 \mathrm{~mm}$ in step of $4 \mathrm{~mm}$. Table 3 gives the first five natural frequencies of the beam by CEM method and compares with those from Sinha et al. and the experimental measurement. The results from CEM are found closer to the experimental prediction than those in Sinha et al. The above comparisons show that the CEM approach of modeling a beam with crack(s) is accurate for the vibration analysis. A significant advantage of the model is the much lesser number of DOFs in the resulting finite element model of the structure.

\subsubsection{Forced vibration analysis for a cracked simply supported beam}

The forced vibration analysis for a simply supported cracked beam is conducted in this section. The effects of the presence of crack on the dynamic response of the beam is investigated. The parameters of the beam under study are taken as: Young's modulus $E=28 \mathrm{GPa}$, width $\mathrm{w}=200 \mathrm{~mm}$, depth $\mathrm{d}=200 \mathrm{~mm}$, length $\mathrm{L}=8.0 \mathrm{~m}$, mass density $\rho=2500 \mathrm{~kg} / \mathrm{m}^{3}$. Two cases are investigated in the following.

Effect of crack depth on the dynamic response

An impulsive force is assumed to act at mid-span of the beam with a magnitude of $100 \mathrm{~N}$, the force starts to act on the beam from the beginning and lasts for 0.1 second. The time step is $0.002 s$ in calculating the dynamic response. Rayleigh damping model is adopted in the calculation with 0.01 and 0.02 as the first two modal damping ratios.

Figure 7 shows comparison on the acceleration response at the $1 / 4$ span of the beam for different crack depth. The crack is assumed to be at the mid-span of the beam. From this figure, one can see that the crack depth has significant effect on the dynamic response of the beam.

\section{Effect of crack location on the dynamic response}

Figure 8 shows comparison on the acceleration response at the $1 / 4$ span of the beam for different crack locations with a fixed crack depth $d_{c} / d=0.3$. The crack is assumed to be at the $0.1 \mathrm{~L}, 0.2 \mathrm{~L}, 0.3 \mathrm{~L}, 0.4 \mathrm{~L}$, and $0.5 \mathrm{~L}$ of the beam. From this figure, one can see that the response changes with the crack location.

These studies show that the effect of the crack on the dynamic response is significant, so it is feasible to identify crack from measured structural dynamic responses.

\section{Conclusion}

The composite element method is proposed for both free and forced vibration analyses of beams with multiple steps. As the composite beam element is of a one-element-one-member configuration, modeling with this type of element would not need to take into account the discontinuity between different parts of the beam. The accuracy of this new composite element has been compared satisfactorily with existing results. One advantage of the 
method proposed is that it can be extended easily to deal with beams consisting of an arbitrary number of non-uniform segments. Regarding the free and forced vibration analysis for cracked beam using composite element, modelling with this type of element would allow the automatic inclusion of interaction effect between adjacent local damages in the finite element model. The accuracy of the present method has been compared satisfactory with existing model and experimental results.

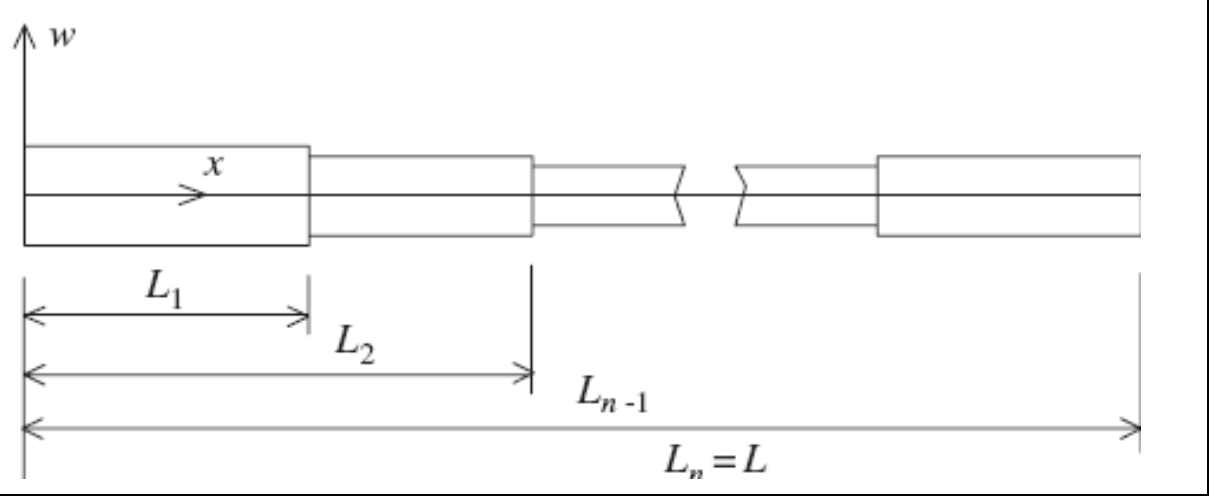

Fig. 1. Sketch of the stepped free-free beam with $\mathrm{n}$ segments

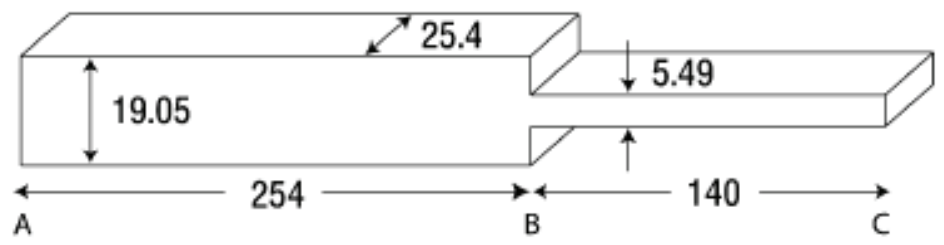

Fig. 2. Sketch of the stepped free-free beam in Koplow et al. (2006). Dimension in millimetre

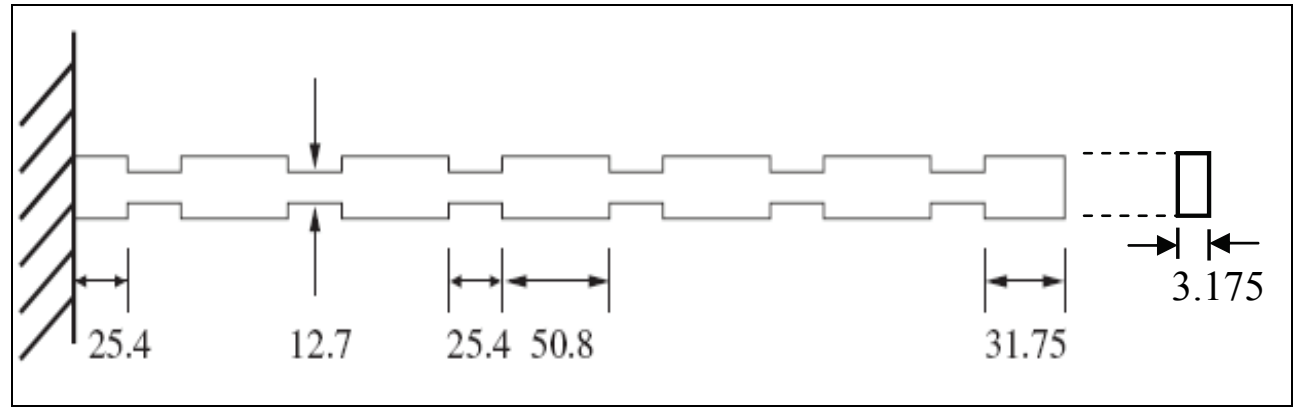

Fig. 3. Cantilever beam in Jaworski and Dowell (2008) with up and down steps. Dimension in millimeter 

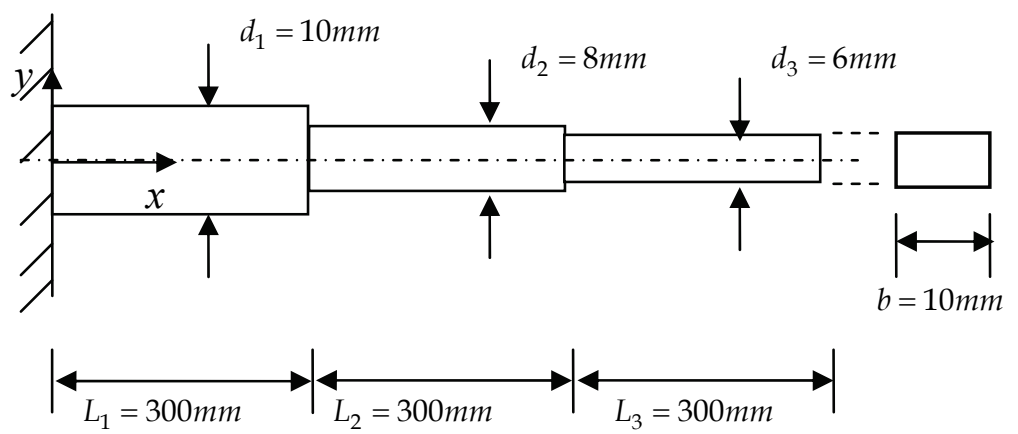

Fig. 4. Sketch of the stepped cantilever beam (dimensions are not scaled)
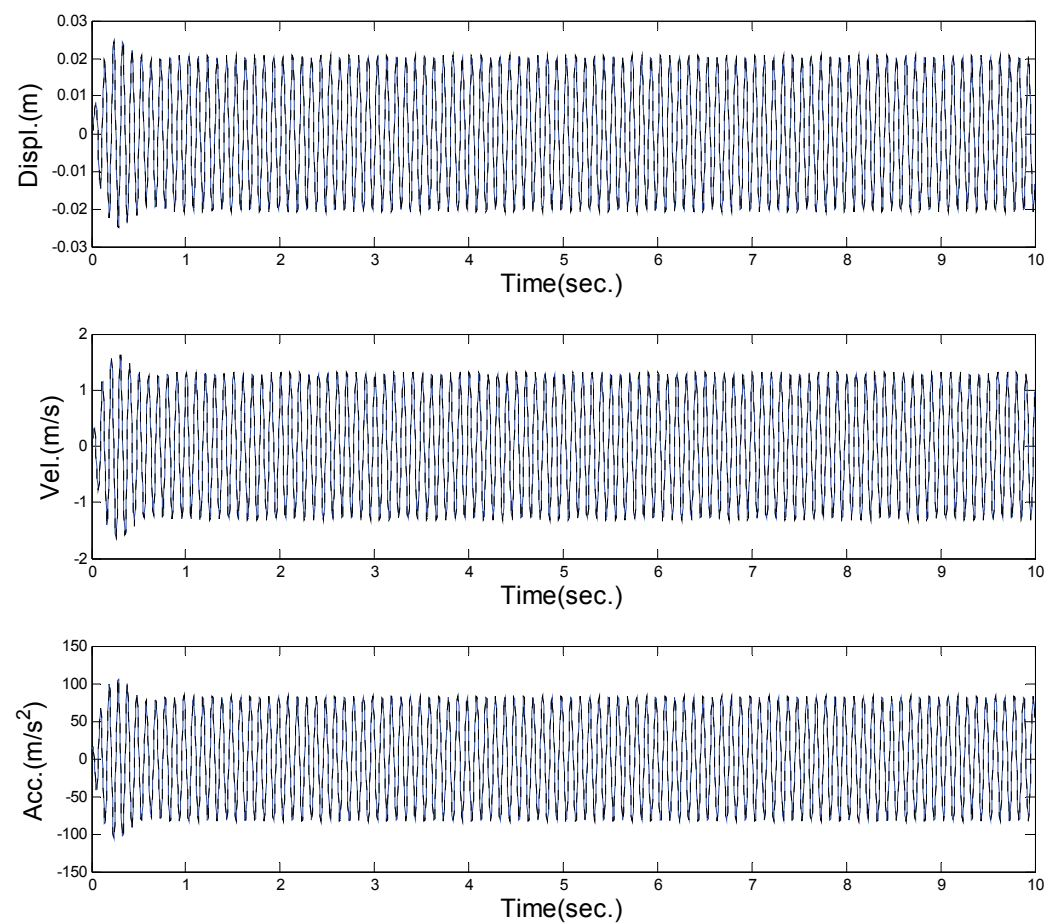

Fig. 5. Forced vibration dynamic response comparison between the CEM and FEM(- Solid: CEM; -- Dashed: FEM) 

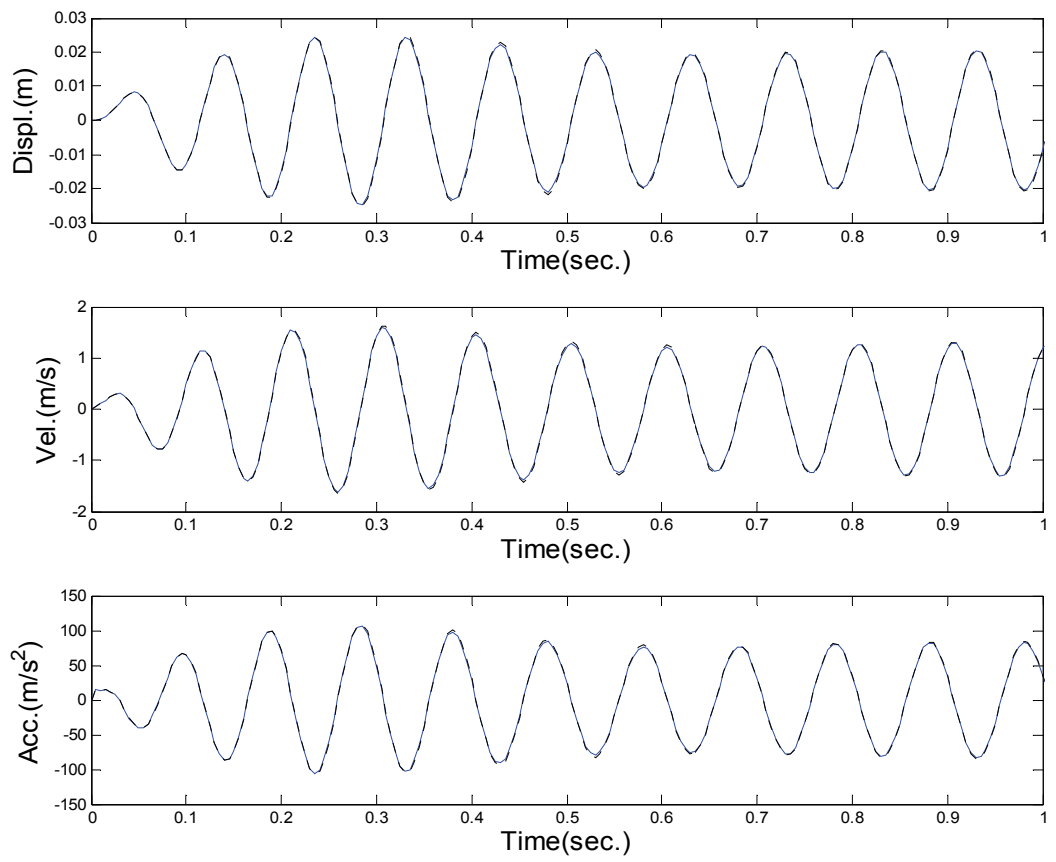

Fig. 6. Forced vibration dynamic response comparison between the CEM and FEM (a close view; - Solid: CEM, -- Dashed: FEM)

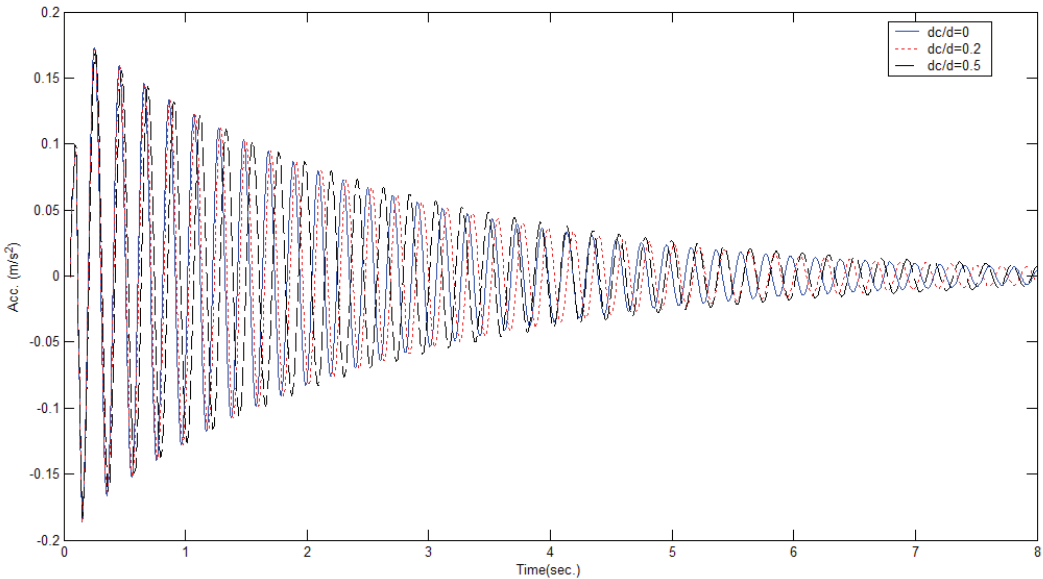

Fig. 7. Comparison on the dynamic responses for different crack depth 


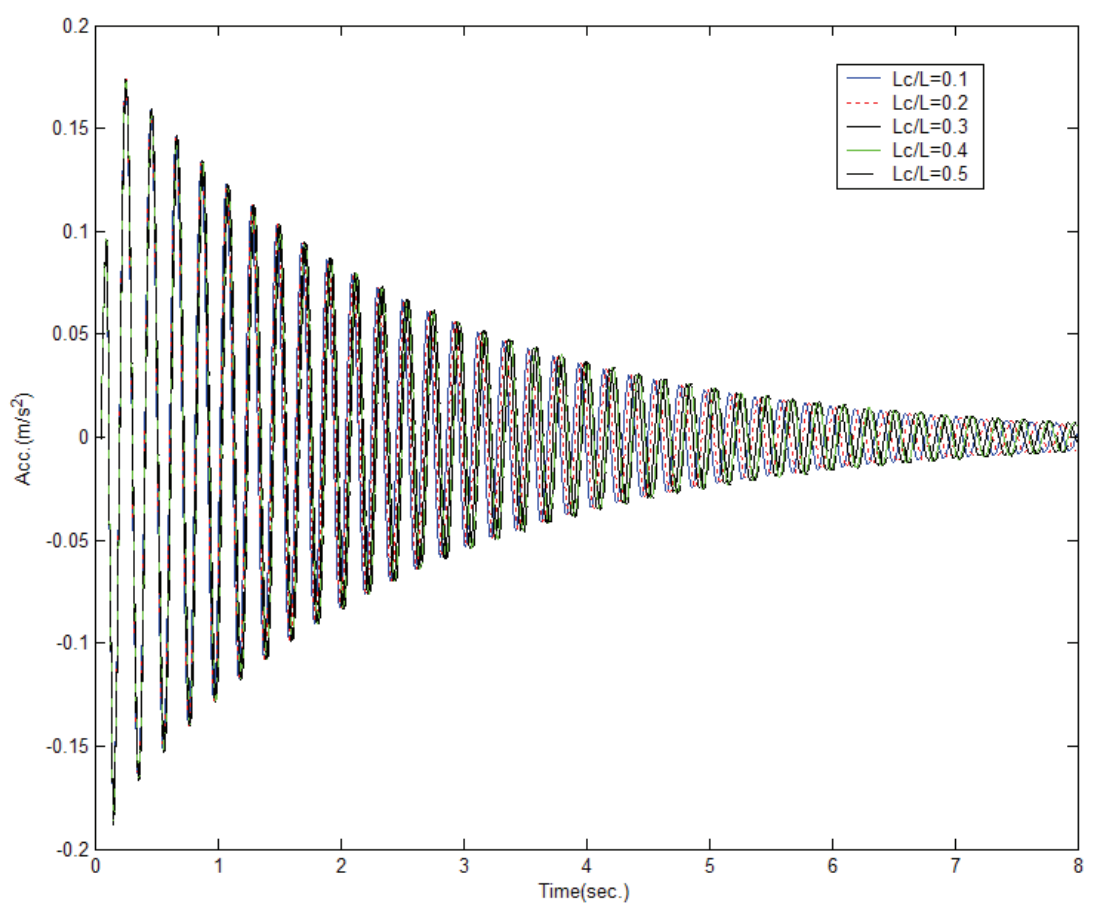

Fig. 8. Comparison on the dynamic responses for different crack location

\begin{tabular}{|c|c|c|c|c|c|c|c|c|}
\hline \multirow{2}{*}{ Mode } & Present & \multicolumn{7}{|c|}{ Jaworski and Dowell (2008) } \\
\cline { 2 - 9 } & CEM & Rayleigh-Ritz & CMA & \multicolumn{4}{|c|}{ ANSYS } & \multirow{2}{*}{ Experiment } \\
\cline { 2 - 9 } & Euler & Euler & Euler & Euler & $\begin{array}{c}\text { Timoshenk } \\
\text { o }\end{array}$ & 2D Shell & 3D Solid & \\
\hline$\omega_{1 B}$ & 10.758 & 10.752 & 10.816 & 10.775 & 10.745 & 10.44 & 10.46 & 10.63 \\
\hline$\omega_{2 B}$ & 67.553 & 67.429 & 67.463 & 67.469 & 67.456 & 65.54 & 65.70 & 66.75 \\
\hline$\omega_{1 C}$ & 54.699 & 54.795 & 54.985 & 54.469 & 54.429 & 49.62 & 49.83 & 49.38 \\
\hline
\end{tabular}

Table 1. Natural frequencies [Hz] comparison for the stepped beam in Jaworski and Dowell (2008)

Note: $\omega_{1 B}, \omega_{2 B}$ are the first and second out-of-plane bending mode frequencies, respectively.

$\omega_{1 c}$ denotes the first in-plane bending mode frequency.

CMA represents component modal analysis. 


\begin{tabular}{|c|c|c|c|c|c|c|c|c|c|c|c|}
\hline \multirow{2}{*}{$\begin{array}{c}\text { Mod } \\
\mathrm{e}\end{array}$} & \multicolumn{2}{|c|}{ No crack } & \multicolumn{3}{|c|}{$\begin{array}{l}d_{c 1}=4 \mathrm{~mm} \text { at } \\
x_{1}=595 \mathrm{~mm}\end{array}$} & \multicolumn{3}{|c|}{$\begin{array}{l}d_{c 1}=8 \mathrm{~mm} \text { at } \\
x_{1}=595 \mathrm{~mm}\end{array}$} & \multicolumn{3}{|c|}{$\begin{aligned} d_{c 1} & =12 \mathrm{~mm} \text { at } \\
x_{1} & =595 \mathrm{~mm}\end{aligned}$} \\
\hline & Exp. & $\begin{array}{l}\text { Propos } \\
\text { ed }\end{array}$ & Exp. & $\begin{array}{l}\text { Sinha et } \\
\text { al.(2002) }\end{array}$ & $\begin{array}{c}\text { Propos } \\
\text { ed }\end{array}$ & Exp. & $\begin{array}{l}\text { Sinha et } \\
\text { al.(2002) }\end{array}$ & $\begin{array}{c}\text { Propose } \\
\text { d }\end{array}$ & Exp. & $\begin{array}{l}\text { Sinha et } \\
\text { al.(2002) }\end{array}$ & $\begin{array}{c}\text { Propos } \\
\text { ed }\end{array}$ \\
\hline 1 & 40.000 & 39.770 & 39.688 & 39.379 & 39.490 & 39.375 & 39.094 & 39.242 & 39.063 & 38.857 & 38.869 \\
\hline 2 & 109.688 & 109.340 & 109.063 & 108.206 & 108.633 & 108.125 & 107.132 & 107.670 & 105.938 & 106.278 & 106.293 \\
\hline 3 & 215.000 & 214.795 & 215.000 & 214.087 & 214.230 & 214.688 & 213.825 & 213.986 & 214.375 & 213.622 & 213.631 \\
\hline 4 & 355.000 & 354.853 & 354.688 & 353.107 & 353.683 & 353.438 & 351.872 & 352.524 & 350.625 & 350.881 & 350.921 \\
\hline 5 & 528.750 & 529.601 & 527.188 & 524.696 & 526.540 & 522.812 & 520.452 & 522.448 & 513.125 & 517.219 & 517.003 \\
\hline
\end{tabular}

Table 2. Comparison of natural frequencies $(\mathrm{Hz})$ of the aluminium free-free beam with one crack in Sinha et al.(2002)

\begin{tabular}{|c|c|c|c|c|c|c|c|c|c|c|c|}
\hline \multirow[t]{2}{*}{$\begin{array}{c}\text { Mod } \\
\mathrm{e}\end{array}$} & \multicolumn{2}{|c|}{ No crack } & \multicolumn{3}{|c|}{$\begin{aligned} d_{c 1} & =12 \mathrm{~mm} \text { at } \\
x_{1} & =595 \mathrm{~mm} \\
d_{c 2} & =4 \mathrm{~mm} \mathrm{at} \\
x_{2} & =800 \mathrm{~mm}\end{aligned}$} & \multicolumn{3}{|c|}{$\begin{array}{l}d_{c 1}=12 \mathrm{~mm} \text { at } \\
x_{1}=595 \mathrm{~mm} \\
d_{c 2}=8 \mathrm{~mm} \text { at } \\
x_{2}=800 \mathrm{~mm}\end{array}$} & \multicolumn{3}{|c|}{$\begin{aligned} d_{c 1} & =12 \mathrm{~mm} \text { at } \\
x_{1} & =595 \mathrm{~mm} \\
d_{c 2} & =12 \mathrm{~mm} \text { at } \\
x_{2} & =800 \mathrm{~mm}\end{aligned}$} \\
\hline & Exp. & $\begin{array}{l}\text { Propos } \\
\text { ed }\end{array}$ & Exp. & $\begin{array}{l}\text { Sinha et } \\
\text { al.(2002) }\end{array}$ & $\begin{array}{c}\text { Propos } \\
\text { ed }\end{array}$ & Exp. & $\begin{array}{l}\text { Sinha et } \\
\text { al.(2002) }\end{array}$ & $\begin{array}{c}\text { Propose } \\
\text { d }\end{array}$ & Exp. & $\begin{array}{l}\text { Sinha et } \\
\text { al.(2002) }\end{array}$ & $\begin{array}{c}\text { Propose } \\
\text { d }\end{array}$ \\
\hline 1 & 40.000 & 39.770 & 38.750 & 38.352 & 38.607 & 38.437 & 37.897 & 38.246 & 37.500 & 37.513 & 37.703 \\
\hline 2 & 109.688 & 109.340 & 105.938 & 105.890 & 106.196 & 105.938 & 105.510 & 106.062 & 105.625 & 105.559 & 105.858 \\
\hline 3 & 215.000 & 214.795 & 213.750 & 212.207 & 212.786 & 212.813 & 210.897 & 211.643 & 210.000 & 209.815 & 209.975 \\
\hline 4 & 355.000 & 354.853 & 350.000 & 348.920 & 349.843 & 349.063 & 347.235 & 348.410 & 345.625 & 345.876 & 346.374 \\
\hline 5 & 528.750 & 529.601 & 512.500 & 514.575 & 514.735 & 511.250 & 512.903 & 513.044 & 507.500 & 510.560 & 510.633 \\
\hline
\end{tabular}

Table 3. Comparison of natural frequencies $(\mathrm{Hz})$ of the aluminium free-free beam with two cracks in Sinha et al.(2002) 


\section{References}

Balasubramanian T.S. \& Subramanian G. (1985). On the performance of a four-degree-offreedom per node element for stepped beam analysis and higher frequency estimation. Journal of Sound and Vibration, Vol.99, No.4, 563-567, ISSN: 0022-460X.

Bapat C.N \& Bapat C. (1987). Natural frequencies of a beam with non-classical boundary conditions and concentrated masses. Journal of Sound and Vibration, Vol.112, No.1, 177-182, ISSN: 0022-460X.

Chaudhari T.D \& Maiti S.K. (2000). A study of vibration geometrically segmented beams with and without crack. International Journal of Solids and Structures, Vol. 37, 761-779, ISSN: 0020-7683.

Christides A. \& Barr A.D.S. (1984). One dimensional theory of cracked Bernoulli-Euler beams. International Journal of Mechanical Science, Vol. 26, 639-648, ISSN: 0020-7403.

De Rosa M.A. (1994). Free vibration of stepped beams with elastic ends. Journal of Sound and Vibration, Vol.173, No.4, 557-563, ISSN: 0022-460X.

Jang S.K. \& Bert C.W. (1989). Free vibrations of stepped beams: exact and numerical solutions. Journal of Sound and Vibration, Vol. 130, No.2, 342-346, ISSN: 0022-460X.

Jaworski J.W. \& Dowell E.H. (2008). Free vibration of a cantilevered beam with multiple steps: Comparison of several theoretical methods with experiment. Journal of Sound and Vibration, Vol.312, No. 4-5, 713-725, ISSN: 0022-460X.

Lee J. \& Bergman L.A. (1994). Vibration of stepped beams and rectangular plates by an elemental dynamic flexibility method. Journal of Sound and Vibration, Vol. 171, No.5, 617-640, ISSN: 0022-460X.

Lu Z.R. \& Law S.S. (2009). Dynamic condition assessment of a cracked beam with the composite element model. Mechanical Systems and Signal Processing, Vol. 23, No. 3, 415-431, ISSN: 0888-3270.

Michael A. Koplow, Abhijit Bhattacharyya and Brian P. Mann. (2006). Closed form solutions for the dynamic response of Euler-Bernoulli beams with step changes in cross section. Journal of Sound and Vibration, Vol.295, No.1-2, 214-225, ISSN: 0022-460X.

Pandey A.K., Biswas M. \& Samman M.M. (1991). Damage detection from change in curvature mode shapes. Journal of Sound and Vibration, Vol.145, 321-332, ISSN: 0022460X.

Pandey A.K \& Biswas M. (1994). Damage detection in structures using change in flexibility. Journal of Sound and Vibration, Vol.169, 3-17, ISSN: 0022-460X.

Rizos P.F; Aspragathos N. \& Dimarogonas A.D. (1990). Identification of crack location and magnitude in a cantilever beam. Journal of Sound and Vibration, Vol.138, 381-388, ISSN: 0022-460X.

Sinha J.K; Friswell M.I \& Edwards S. (2002). Simplified models for the location of cracks in beam structures using measured vibration data. Journal of Sound and Vibration, Vol. 251, No.1, 13-38, ISSN: 0022-460X. 
Zeng P. (1998). Composite element method for vibration analysis of structure, Part II: $C^{1}$ Element (Beam). Journal of Sound and Vibration, Vol. 218, No.4, 658-696, ISSN: 0022-460X. 


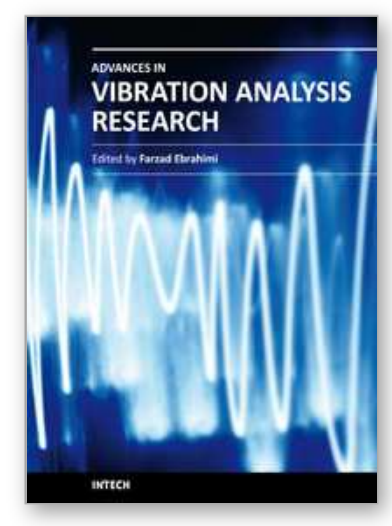

\author{
Advances in Vibration Analysis Research \\ Edited by Dr. Farzad Ebrahimi
}

ISBN 978-953-307-209-8

Hard cover, 456 pages

Publisher InTech

Published online 04, April, 2011

Published in print edition April, 2011

Vibrations are extremely important in all areas of human activities, for all sciences, technologies and industrial applications. Sometimes these Vibrations are useful but other times they are undesirable. In any case, understanding and analysis of vibrations are crucial. This book reports on the state of the art research and development findings on this very broad matter through 22 original and innovative research studies exhibiting various investigation directions. The present book is a result of contributions of experts from international scientific community working in different aspects of vibration analysis. The text is addressed not only to researchers, but also to professional engineers, students and other experts in a variety of disciplines, both academic and industrial seeking to gain a better understanding of what has been done in the field recently, and what kind of open problems are in this area.

\title{
How to reference
}

In order to correctly reference this scholarly work, feel free to copy and paste the following:

Z.R. Lu, M. Huang and J.K. Liu (2011). Vibration Analysis of Beams with and without Cracks Using the Composite Element Model, Advances in Vibration Analysis Research, Dr. Farzad Ebrahimi (Ed.), ISBN: 978953-307-209-8, InTech, Available from: http://www.intechopen.com/books/advances-in-vibration-analysisresearch/vibration-analysis-of-beams-with-and-without-cracks-using-the-composite-element-model

\section{INTECH}

open science | open minds

\author{
InTech Europe \\ University Campus STeP Ri \\ Slavka Krautzeka 83/A \\ 51000 Rijeka, Croatia \\ Phone: +385 (51) 770447 \\ Fax: +385 (51) 686166 \\ www.intechopen.com
}

\author{
InTech China \\ Unit 405, Office Block, Hotel Equatorial Shanghai \\ No.65, Yan An Road (West), Shanghai, 200040, China \\ 中国上海市延安西路65号上海国际贵都大饭店办公楼 405 单元 \\ Phone: +86-21-62489820 \\ Fax: +86-21-62489821
}


(C) 2011 The Author(s). Licensee IntechOpen. This chapter is distributed under the terms of the Creative Commons Attribution-NonCommercialShareAlike-3.0 License, which permits use, distribution and reproduction for non-commercial purposes, provided the original is properly cited and derivative works building on this content are distributed under the same license. 